\title{
Hunt kultusloomana eesti rahvatraditsioonis
}

\begin{abstract}
Ilmar Rootsi
Teesid: Eestlaste rahvapärimus hundist on mitmekülgne ja rikkalik, jättes varju teised metsloomad, sh karu. See on välja kasvanud suures osas karjakasvatuse pinnalt, sest pidevalt karja ohustavaid hunte tuli kariloomadest eemal hoida. Seda püüti teha nii reaalsete vahenditega kui ka maagiavõtetega. Et kasu polnud ühest ega teisest, sai hundist esivanematele loodusjõud, kellega tuli igapäevaelus arvestada ja keda pidi respekteerima. Nii tuli tunnustada hundi õigust saagile ja saagiga lahkuvat hunti ei tohtinud segada ega hurjutada, ka ei tohtinud inimene kasutada hundi murtud looma. Usuti sedagi, et koduloomi murdes toob hunt neile ühtlasi sigivust.

Respektist hundi ees räägib juba üksi talle antud eufemismide väga suur hulk. Sellele viitavad ka hundiga kohtumisel talle "au" andmine, so lahkete sõnadega pöördumine. Kättemaksu kartusel püüti hoiduda tema pesa rüüstamisest, seda just kodu lähedal. Hundilt loodeti ka abi ja kaitset: a) tema kehaosadelt, organitelt (näit rahvameditsiinis) ja b) hundilt endalt (näit inimese kaitsjana kodukäijate ja teiste pahade vaimude eest.
\end{abstract}

Märksõnad: eufemismid, heraldika, hunt, maagia, rahvameditsiin, rahvausund

Ega hunt olegi nii hull kui ta on hall.

(Eesti vanasõna)

Tõelist hundikultust - jumaldavat austamist, nagu seda on esinenud mõne teise rahva (peamiselt loodusrahvaste) usundeis, pole Eestis olnud. Mujal on see esmalt lähtunud hundist kui tootemloomast ${ }^{1}$ koos kõige sellest tulenevaga - loomast, keda ei tapetud ja kelle liha ei söödud, keda on toidetud ja kellele ohvreid toodud, kellele on austust avaldatud nii looma eluajal kui ka pärast tema surma; loomast, kellelt on loodetud abi ja kaitset igas elujuhtumis kuni uskumiseni, et tal oli osa jumala abilisena inimese loomisel, pidades teda saadikuks jumala juurde, pühaks loomaks.

Eestlaste rahvausund ei kõnele hundi pidamisest tootemloomaks. Ometi tuleb tunnistada, et tegemist on metsloomaga, kellest jutustav rahvapärimus 
on kõige mitmekülgsem ja rikkalikum, jättes varju teised metsloomad, sealhulgas karu.

Küti- ja kalastajakultuuris polnud hundil kaugeltki niisugust tähtsust kui maaviljeluse ja karjakasvatusega tegeleva rahva puhul. Meile tuntud pärimused hundist on välja kasvanud suures osas karjakasvatuse pinnalt, sest pidevalt karja ohustavaid hunte tuli oma kariloomadest eemal hoida. Nii reaalsete vahendite kui maagiavõtetega - taigade ja loitsudega.

Hunt oli meie esivanemate silmis vääramatu loodusjõud, kellega tuli igapäevaelus arvestada ja keda tuli ka respekteerida. Nii võibki eestlaste hundipärimustes täheldada ühe olulise osana nende tõrjemaagiat koos eluõiguse tunnustamisega. Tähelepanu väärib tõrjemaagiliste loitsude üldine suunitlus: loitsusõnades ei taotleta hundi füüsilist hävitamist, vaid tema suunamist eemale oma karjast, kusagile mujale - sohu, laande, murdma pigem puid ja kive. Üks kohaseid näiteid on kirja pandud 19. sajandi lõpukümnendil Vigala kihelkonnast, kus karjane pöördub hundi poole järgmiste sõnadega:

Metsa sikku, metsa sokku, metsa kuldane kuningas, metsa halli harvalõuga, metsa peni pikkalõuga! Ära salva salajalta, ära näppa nägemata, ära puutu minu pulli, ära katsu minu karja! Mine sohu sobistama, mine laande luusimaie, pikke puida murdemaie, kivi külga kiskumaie! (H III 18, 400/1(5) < Vigala (1894)).

Nii soovis karjane. Tegelikkuses tunnustati hundi õigust saagile, sellega minekul järgiti tema segamise ja ka tema saagi kasutamise keeldu.

\section{Eestlaste pärimused, mis kõnelevad lugupidamisest hundi vastu}

Respektist hundi vastu kõneleb ainuüksi tema kohta kasutatavate eufemismide-peitenimede väga suur hulk, mis tuleneb esmalt juba hirmust tema ees. Hundil on pallu nimesid, ütetse, et 99 nime olla, arvas kunagi Liisa Saul Kullamaa kihelkonnast (ERA II 16, 411 (18) < Kullamaa (1929)). Tegelikult on neid ligi viis korda enam - see on mitu korda rohkem kui meie kõigi teiste kiskjate 


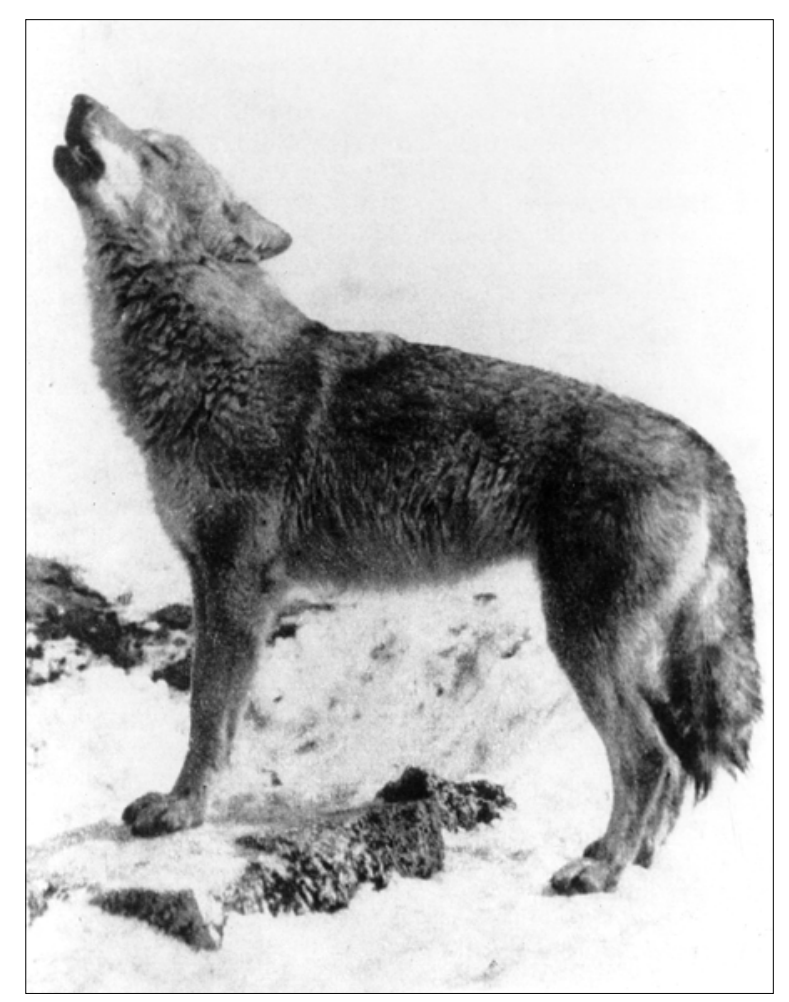

Huntide ulgumises nähti kõigepealt ilmaennet. Ajakirjast Wissenschaft und Fortschritt 1977, nr 4, lk 183.

(nirgist karuni) nimesid kokku. Mõistagi - ei ole ju karu, ilves, rebane ega teised kiskjad esivanemate elus jahiloomadena ega kahju tekitajatena kunagi etendanud seda osa, mis hunt karja laastava kiskjana. Miks siis ei võinud hunti (aga ka teisi loomi) nimetada õige nimega?

Veel 19. sajandil valitses kujutelm, et loomadel on kõik inimlikud omadused, sealhulgas inimkõne mõistmise võime. Looma õige nimega nimetamine kutsuvat ta kohe kohale. Sellepärast kardeti paljusid loomi, eriti aga suuri ja ohtlikke kiskjaid nimetada õige nimega. Nagu kirjutas Johann Wilhelm Ludwig Luce (1750-1842), olevat tema aja saarlased peljanud rääkida hundist otsesõnu, teda nimeti vanaks halliks, vanaks julgeks, metsalinnuks või lihtsalt metsaks (Luce 1827: 64-65). Hundi nimetamist tuli eriti vältida karjas olles ja söögi ajal, et temas mitte isu äratada ja teda ligi kutsuda. Isegi kalasaagist pidid püüdjad ilma jääma, kui püügi juures nimetada mõne metslooma nime (E 26306 (4) < Haljala (1896)); ERA II 148, 62 (34B) < Märjamaa (1936)). Samasugust aupaklikkust näitasid hundi vastu üles ka naaberrahvad. Leedus ei söandatud koguni hundi ulgumist nimetada muuks kui lauluks (Afanasjev 1865: 742). 
Lugupidamisest hundi vastu räägivad paljud pärimused. Tunnustatud oli tema õigus saagile, selle paratamatu kaotusega arvestati igas talus kui hundi "jaoga", mille ta pidi saama. See paratamatu ohver oli mõeldud nagu lepituseks, lootuses, et siis jätab hunt ülejäänud karja rahule või teeb vähem kahju. Näiteks 1898. aastal pajatas 78-aastane V. Laur Vastseliina kihelkonnast nii:

Kuna enne susse mõtsah inamb oll, ku parhilla jänessit, nink küla karjuste hagemine hagemisest es lõpegi, sest et susse egapäivi külä karjale kutsmada külälisis tull [---]. Niisugusel soerikkal aal tähend ega talo pernaane üte ehk kats voonakest soe jaos uma suuga arr, sest et ega aasta vana kriim silm nii paljo, ehk mõni kõrd rohkembgi uma toidu pääle tarvitas. Nii sama tähendedi põrssite, kitse poige, vasikide nink varsu pääle iks soe jago ja üteldi tuud jo sinna kogoni luudu olevat, millest ülelija kahidaki ei massa, sest tuu om perra jäänü eläjä õnnele kahjolik... (H II 61, 228/30 (23) < Vastseliina (1898)).

Või sealtsamast teine samalaadne:

Õga susi ilma söömäldä saa. Talle om ka jago säet [---]. Ma esi mälehta, et ku küläh noori varssu oll, sõss ku edimätsel ööl öütsi lätsi, sõss peremees hõigas ö̈̈dsi man, et "No susi, ku sööt, sõss söö edimätsel ööl ar, a peräst ar putku!” Ku kinkõlgi varsa sei ar, sõss et: “Oh ta timä jago, ta tälle lubat."

Nii rääkis 79-aastane T. Külmläte (ERA II 286, 24/5 (14) < Vastseliina (1940)). Kunagine austav suhtumine hundi “jaosse" peegeldub ka järgnevas tekstis:

Hunt võtnud vanasti kaks seapõrsast korraga suhe. Peremees ütlend: "Kurati loll, ajab kaks korraga, kas katkestab ennast ä̈̈. Ons soole neid keeltud, tule vii teine teise korra jälle!”(ERA II 187, 397/8 (136a) < Karja (1938)).

Ehkki hundid talvekuudel tihti taluõue tungisid ja koeri ära viisid, pole neid sellepärast hukka mõistetud. Siitki oli neil oma jagu saada - sigimiseks. Usuti, et kui emahunt enne jooksuaja algust koeraliha süüa ei saa, siis ta ei tiinestu (E 16360 (11) < Tarvastu (1895)). Kambja pool lisati veel juurde, et vähemalt üte koera peab aastan ära sööma (ERA II 63, 335 (8) < Kambja (1933)).

Huvitaval kombel on sama uskumus tuntud ka meist kaugel elaval rahval - bulgaarlastel (Jermolov 1905: 252).

On üllatav, et mälestusi hundi jaost on liikunud rahva hulgas veel lähiminevikus. Nii teatas 1977. aastal 70-aastane Rudolf Sordla Võnnu kandist:

Kui mingi loom, näiteks lammas ära tappeti, siis pidi esimene kaelalüli ehk -jakk metsa hundi jaoks visatama [---]. Kuid minu lapsepõlves hunti- 
sid enam metsades ei olnud, anti need koertele ehk kassidele [---]. Seda kutsuti hundi jagu ja ise seda ei söödud (RKM II 328, 244 < Võnnu (1977)).

Nähtavasti on see ülestähendus jäänuk kunagisest kombest, millega taotleti karjale kaitset, tervist ja sigivust. Samalaadseid mälestusi on talletatud mujaltki. Lüganuse kihelkonnas tehti seda hingede- ehk jaguajal novembris, mil viidi huntidele metsa kivide ja kändude peale süüa (ERA II 28, 255/6 (24) < Lüganuse (1930)). Metsavaht Jaak P. Sõggel teatas aga Saarde kohta, et kui talvel olevat metsa viidud surnud vasikas või lambatall, siis sinna karja polevat hunt tulnudki (ERM, KV 53, $849<$ Saarde (1949)).

Varasemast ajast pärineb sellisest ohverdamise kombest teateid Võrumaalt Johann Wolfgang Boeclerilt (Boecler 1854: 37) ja Hiiumaalt Reigi kihelkonnast Carl Russwurmilt (Russwurm 1855: 91) ning Aleksei Haruzinilt (Haruzin 1896: 13-14). Oma raamatu Eibofolke oder die Schweden an den Küsten Ehstlands und auf Runö esimeses osas tõi C. Russwurm ära Reigi koguduse õpetaja 1709. aasta kaebuse oma koguduse liikmete peale, kes käivad Püha Hannose mäel asuva vana kabeli juures paganlikele jumalatele ohverdamas, et pääseda huntide tehtavast kahjust ja saada head räimesaaki (Russwurm 1855: 91).

Ka meie lõunanaabrite lätlaste kohta on andmeid, et igal aastal detsembris ohverdati traditsioonilisel riitusel kits - lepituseks huntidele ja lootuses, et nad siis teevad suvel karjale vähem kahju (Böckler \& Einhorn \& Engelken 1857: 55-56).

Ohvrilooma või -anni eraldasid hundile teisedki rahvad: venelased, serblased, makedoonlased, poolakad, laplased jt. Venemaal viidi metsa jäetud lammas ohvriks huntide peremehele Tšestnoi Lesale, kes olevat vahel esinenud valge hundi kujul (Dobrovolski 1901: 135-136; Gura 1997: 149).

Tunnistades hundi õigust polnud lubatud saagiga lahkuvat hunti ka segada, seda eriti väljaspool oma majapidamise piire, muidu tasub kätte (ERA II 197, $220<$ Haljala (1938)).

Kui susi karjas käib ja selle maa piirist üle läheb, siis enam ei tohi teda taga ajada-mille ta on saanud, selle on saanud. Kord üks peremees oli võora nurme peal soe käest hane ära võtnud, pidi aga oma künnihärja sutele lubama (H II 3, 562/3 < Vastseliina (1888)).

Hunti ei võivat siis isegi hurjutada, rääkimata tema saagi puutumisest, ses nakkas tä kõvastõ keusama ja tege tülütäjäle kui taht kahju, s.o tuleb karja jälle tagasi (H II 51, 474 (3) < Rõuge (1894)).

Üldse valitses arvamus, et hunti asjata hurjutada ei tohi, muidu võib ta karja kallale tulla (H II 3, 551 (36) < Vastseliina (1888)).

Loomulikult polnud inimesel lubatud kasutada hundi murtud saaki.

Hundi murtud looma liha ei tohi sü̈̈a, mis täma soagist ôli, muidu hunt teeb kurja, hakkab oma osa kätte nõudma, [või kui julged seda siiski 
teha] elad ainult selle hundi elupäevad (AES, I < Palamuse (1938)); ERA II 297, 423/4 (15) < Tallinn (1941)).

Ka slaavi ja germaani rahvaste kohta on teateid, et hundilt ei tohtinud saaki ära võtta ega tema murtud loomade liha kasutada, sest usuti, et hunt murrab ainult selle looma, kelle jumal on talle andnud (Afanasjev 1865: 710).

Aupaklikult tuli suhtuda mitte ainult saaki kandvasse hunti, vaid temast tuli lugu pidada ka muudel puhkudel. Sai teekäija juhuslikult hundiga kokku, ei võinud ta teda hurjutada, vaid pidi ohutuse mõttes pöörduma tema poole sõnadega: Külamees! Kääna sa oma teed, ma lähen oma teed (H, Wiedemann 1, 304 < Setu, 1870. aastad) või Külamiis, puul tiid mullõ, puul sullõ! (H II 56, $1028(60)<$ Rõuge (1896)).

Vene talupojad pöördusid huntidega kohtudes nende poole erilise aukartlikkusega: Здравствуйте, молодцы! [Tervist noormehed!] või Здравствуйте, брацы, пропустите, пожалуйста, мне дорогу! [Tervist, veljed, andke mulle palun teed!] Usuti, et kui rääkida huntidega sõbralikult ja lugupidavalt, ei tule nad kallale ning lähevad oma teed (Dobrovolski 1901: 135-136; Gura 1997: 152).

Arvatava kättemaksu kartusel püüti hoiduda ka hundi pesa rüüstamisest, eriti siis, kui see asus kodu lähedal. Samas teati, et hunt oma pesa lähiümbrusest ei murra. Pealegi usuti, et hundi ootamatul nägemisel võis inimene kaotada hääle, mida raviti sümboolselt kaevu hõigates.

Kokkuvõttes võib öelda, et parem oli end selle looma ellu mitte segada, nagu kirjutas selle kohta ka Otto Wilhelm Masing:

...kes hunti, nõida ehk rotti taga kiusab, otsib õnnetust: neid kolm peab rahule jätma, kui nende poolest rahu peab ollema [---]. Seda on jo vanast teada, et kes hunta, nõidu ja rottisid hakkavad taga kiusama, et nemad ennast nende viha alla saatnud ja nemad neile pärast suurt kahju teinud (Marahwa Näddala-Leht 1823, 9. II: 48).

Hästi haakub eeltooduga ka eskimote tarkus:

Meie ei lase neid kunagi, kui nad käivad oma teed ega ründa ise. Loom mõistab paljugi. Kui teda solvad, maksab ta sulle kätte - tuleb ja tapab su põdrad (Šatalov 1978: 186 [Volk 1985: 549]).

Nii rääkisid eskimod veel 1930-ndatel aastatel.

Leidub aga ka teateid uskumusest, et karja murdes toob hunt sellele ühtlasi sigivust. Nii öeldi Saaremaal Kärla kihelkonnas:

Kui hunt hanisi murdnud, siis piab see hani sort mis üle jäänd väga hästi sigima, aga kui rebane ehk koer hanid maha murdnud, siis peab 
need ülejäänud koguni ära rikutud olema, ei pia enam sigima (SKS, Niemi II, 913 (1898)).

Nagu rebast ja koera, on ka karu peetud loomaks, kelle põhjustatud kahju ei too karjale õnnistust. Hundi kohta on arvatud teisiti. Nii räägiti Häädemeestel:

Ku karud loomi lõhkuva, see oleva õnnetuseks, aga kui hundid lambi lõhkuva, see oleva õnnistuseks, siis lambad siginevad hästi (ERA II 168, 662 (88) < Häädemeeste (1937)).

See uskumus näib olevat üsna sügavapõhjaline, sest Põlva kandis on see tuntud ka vanasõnana: Hundi jälin on lammaste õnnistus, aga sia jälis õnnetus (EV 1980, nr 1605). Mõningaid paralleele on siia tuua teistegi rahvaste pärimusest. Näiteks oli lammaste murdmine heaks märgiks ka bulgaarlastel - suurenema pidi lammaste sigivus ja müügiks olevad lambad pidid leidma kiiresti ostjad (Gura 1997: 144). Nagu kirjutas Vladimir Dobrovolski 1901. aastal, olevat vene rahva hulgas valitsenud uskumus (ja seda veel artikli ilmumise ajal), et hundil on suus nii hea kui ka halb hammas. Hea hambaga murdes olevat kari terve ja edenevat hästi (Dobrovolski 1901: 135-136). Analoogiline oli ka laplaste uskumus (Morozova 1973: 138).

\section{Abist ja kaitsest, mida hundilt pidi saama}

Nagu teisedki rahvad, on eestlased lootnud saada abi ja kaitset hundi teatud kehaosadest ja organismist ning isegi hundist endast. Maagiliselt toimivana on nimetatud liha, kõri, koljut, hambaid, saba, karvu ja ekskremente. Need võisid anda abi tervisehädades, tagada edu ja kasu majapidamises ja töös, pakkuda kaitset kurjade jõudude eest ning tuua isikliku elu õnne.

Mujal maailmas on lisaks seitsmele nimetatule kasutust leidnud veel hundi maks, rasv, sapp, nahk, süda, veri, kopsud, soolikad, suguorganid, luud, kõõlused, pea, silm, keel, käpad, küünised jne. Peaaegu kõike, mis sellelt loomalt saada võis, oskasid inimesed oma huvides ühel või teisel eesmärgil, ühel või teisel viisil kasutusele võtta. Nendest neli esimest, esmalt maks, seejärel rasv, sapp ja nahk leidsid rahvameditsiinis teistest enam ja mitmekülgsemat kasutust (Der Kleine Pauly 1975: 1387). Näiteks kasutati kuivatatud ja peenestatud maksa maksahaiguste, tuberkuloosi, veetõve, süüfilise ja teiste suguhaiguste, sünnitusvalude, haavade, peavalu, südamehaiguste, igasuguste põletike, üldise nõrkuse, köha ning isegi pahaloomuliste kasvajate ja marutõve raviks (Grosses vollständiges 1748: 508; EM 1783: 71-75). Ühe allika (Bernard 1983: 99) järgi kuulus hundi maks omal ajal koguni võlujookide koostisse. 
Rasva tarvitati tuberkuloosi, reuma, luumurdude, liigeste ja podagra raviks, samuti siseelundite "soojendamiseks" ja raviks. Usbeki naised on lootnud hundirasva joomisest abi sigimatuse puhul. Peale selle kuulus rasv veel mitme rohu koostisse (Fischer 1772: 429; Potapov 1958: 141).

Sappi kasutati peamiselt nahahaiguste tõrjeks, näiteks kirgiisid lööbe ja vistrike puhul. Venemaal määriti hundi sapi või rasvaga haavu, hobustel ka kiinide vakladest põhjustatud muhke, samuti kasutati seda reuma ja muudegi hädade korral (Sabanejev 1872: 88-89, Potapov 1958: 140-141, Gura 1997: 155).

Nahka kasutati epilepsia, nõgestõve, voolmete ja palaviku raviks; kõhuvalude puhul kanti seda vööna ümber keha, karvad seespool; unetuse korral aitas hundinaha alla magama heitmine; hundinahast tehtud sussides käiv mehehakatis loodeti kasvavat tugevaks, julgeks ja sõjakaks meheks jne (Grosses vollständiges 1748: 509; Gubernatis 1874: 452-453).

On huvitav märkida, et hundi mingit kehaosa või organit tarvitati inimese sama kehaosa või elundi raviks. See on rahvameditsiinis tüüpiline: sarnasega ravitakse sarnast, osaga tervikut. Näiteks juba mainitud maksaga tohterdati maksahaigust, kopsuga tiisikust ja astmat, luuga luumurde ja reumat, silmaga haiget silma - parema silmaga paremat, vasakuga vasakut silma jne (Grosses vollständiges 1748: 508; Allgemeine 1873: 143-145).

Nõnda toimiti mujal. Aga kuidas meil?

Esmalt liha kasutamisest. Usuti, et nii hundi- kui ka karuliha söömine aitab liigesereuma ehk jooksva vastu, pealegi pidi uskumuse kohaselt sööja omandama võime arstida teisi inimesi (ERM, KV 33, 2002/3 Rõuge (1938)). Rahvameditsiin tunneb haigust nimega kidi (nari, rodi). See on kõõlusetupe põletik, mis esineb peamiselt käelaba piirkonnas, tekitades käerandmes valu ja liigutamisel krudinat. Haiget kohta tuli lasta hundiliha söönud inimesel hammastega näksida.

Kui kidsi käes [---] sellel inimesel, kes soe liha söönud, närida lasta. Vanasti kutsuti, kui hunt ära oli tapetud, külarahvas kokku hundi liha sööma. Neist, kes soe liha sõivad, saivad hä̈̈d arstid (ERM 151, 91/3 (8) < Rõuge (1920)).

Need "arstid" võisid peale kidihaigete aidata ka poisse, kel näiteks munandid paistes. Nii olevat üks laps tervekski saanud (E 58598 < Võnnu (1926)). Täpselt samuti usuti ka Poolas, kus hundiliha söönu arvati olevat võimeline ravima näksimisega ka paiseid ja muhke (Gura 1997: 154).

Et osa inimesi meil minevikus tõesti sõi hundiliha, kinnitab ka Jakob Benjamin von Fischer oma Liivimaa põllumajandusraamatus (Fischer 1772: 429). Aga mis eesmärgil, seda pole autor maininud. Arvatavasti ei tehtud seda nälja pärast. Nagu rahvas räägib, olevat hundilihast keedetud leent antud ka lastele (ERA II 21, 73 (89) < Setu (1928)). 
Hundiliha pidi aitama koduloomigi. Kui aastatel 1748-1751 möllas Liivi-ja Kuramaal veiste hulgas siberi katk, mil muuseas suri metsades ka hulgaliselt põtru, söödeti veistele soolatud ja seejärel suitsutatud ning peenestatud hundiliha kui universaalset vahendit kõikide hädade puhul (Fischer 1772: 428).

Hundiliha söönu kõrval võis arstimise võime saada ka see, kelle liha hunt ise süüa tahtis. Nii olevat 1860.-1870. aastatel tahtnud hunt Velisel ühest Rööviku-nimelisest metsatalust ära viia väikest poissi Kustat. Isa suutis küll poisi päästa, kuid hundi lõugade vahel saanud poisi käsi vigastada. Kusta käsi paranes, ta kasvas meheks ja hakkas inimesi nende hädades aitama. Usuti, et sellel hundi vigastatud käel on mitme haiguse puhul tervendav mõju.

Hästi mäletan, kellel hambad valutasid, läks Rööviku Kustase juure, et Kustas vajutab hundi kistud käega lõuga, et hambavalu kaoks. Mõnigi mees ütles, et Kustas võtnud hambavalu ära. Ka muude tõbede vastu pidi selle käega õerumine ehk vajutus kergendust tooma.

Nii rääkis 1967. aastal metsavaht Jaan Limberg (RKM II 224, 605 (4) < Märjamaa (1967)).

Mis teistesse rahvastesse puutub, siis on ravivõimaluste loend märksa ulatuslikum. Hundiliha on kasutatud sünnitusvalude leevendamiseks, kuivatatuna ja peenestatuna epilepsia ja struuma raviks, õlis keedetuna podagra puhul, hobustel tiirudest põhjustatud valu vähendamiseks ning veistel verekusemise korral (Gesner 1563: 155; Grosses vollständiges 1748: 509; Onomatologia 1773: 1016; HDA 1987: 768).

Hundi kuivatatud kõrist loodeti kasu mesilaste pidamisel ja isegi viljakasvatamisel. Kevadel pidid tarudest puhastuslennule väljuvad mesilased minema läbi hundi kõri. Sel teel loodeti järgneva suve vältel suurendada esmalt mesilaste töökust, et nad hästi kiskjad oleks, võõrastes puudes käiks ja võõraid mesilasi murraks ning mett rööviks (ERA II 5, 536 < Pärnu-Jaagupi (1928)). Samas pidid nad ise kurja eest kaitstud olema (E 6409 (21) < Ambla (1894)).

Analoogseid teateid hundi kehaosade kasutamisest mesinduses pärineb mujaltki. Nii pandi ka Poolas ja Abhaasias hundi kuivatatud kõri taru lennuava ette, Ukrainas toideti mesilasi tema kõrist valmistatud pulbriga, Venemaal Kaluuga kubermangus olid aga amuletina taru lennuava ees hundi kuivatatud mokad, Serbias hundi küünised või hambad, lisaks mesilas tema kolju. Hundi nina oli mesinike amulett Valgevenes Vitebski kubermangus. Seda kõike tehti ühel eesmärgil - et mesilased ikka rohkem mett koguksid, kasvõi varastades või röövides teistest tarudest (Afanasjev 1865: 765, Tšursin 1929: 9, Zelenin 1929: 56-57; Gura 1997: 153).

Hundi kõri pidi vanade eestlaste meelest edendama ka viljakasvu. Seeme, mis enne külvi oli lastud läbi hundi kõri, loodeti hästi idanevat. Täh vili saap väega hää kasuma (H III 11, 575 (38) < Põlva (1890)). 
Saksamaal aga oli selle toimingu mõtteks hoopis seemnete kaitsmine lindude eest, kes ähvardasid külvi rikkuda (Rantasalo 1919: 103). Veega, mis oli voolanud läbi hundi kõri, olevat ravitud Valgevenes, Bulgaarias ja Poolas kõrihaigusi. Poolas usuti veel, et laps, keda on toidetud läbi hundi kõri, kasvavat hea söögiisuga inimeseks (nagu hunt). Iseenesest mõista pidi hundi kõrist abi olema ka isutuse all kannatajal (Gura 1997: 153, Onomatologia 1773: 1015, Tolstoi 1995: 416).

Hundi kolju leidis nii meil kui ka mujal kasutamist esmalt kaitsevahendina. Kui hundi pea aidas, ei vii tont ega varas vilja ära (E 8478 (99) < Tarvastu (1893)). Ka loodeti koljus hoitud veega laste silmi pestes kaitsta neid haigeksjäämise eest (H II 50, 248 (13) < Laiuse (1895)). Kohti, kus hundi koljut veel hoida, rahvastel jagus. Näiteks tšuktšidel oli see elamus (Haruzina 1909: 226), hantidel, mansidel ja samojeedi rahvastel ohvripaigas (NES 421-422), usbekkidel põllul või aias (Potapov 1958: 140), mõnedel rahvastel veel õueväraval (Der Kleine Pauly 1975: 1387) või elamu ukse juures (HDA 1987: 774), kuid ka tuvilas kaitseks kasside eest (Grosses vollständiges 1748: 508).

Hundi hambaid on teadaolevalt tarvitatud kahel eesmärgil: imikutel hammaste lõikumise kiirendamiseks ja amulettidena, kaitsevahenditena, mida karuhammaste kõrval on kaelas kantud ka Eestis (Moora 1926: 111, Jaanits 1961: 39).

Imikud on hundihambaid suus lutsutanud juba alates antiikajast, läbi keskaja uusajani välja (Die Naturgeschichte 1882: 79, Gesner 1563: 155, Linné 1773: 222). Võib arvata, et see komme on tuntud paljudel rahvastel, sest lõunaslaavlased nimetavadki lapse esimest hammast hundihambaks (HDA 1987: 781).

Et saada ettekujutust hundihammaste kasutamisest, tsiteerin Aleksander Sakseni vanas kirjaviisis avaldatud raamatut Lomisse Öppetusse-ramat... (1842: 92):

Ka hõbbedaga sawad hundi hambad sisse kanditud, ja weikeste lastele kaela ümber seutud, sest, et nemmad siis, kui hakkawad hambaid teggema, sedda suhhu wõiwad wõtta ja hamba lihha seäl külges woiwad öeruda, ja nenda nende hambad siis ussinaminne ja kergeminne wälja woiwad tulla.

Usbekid riputasid hundi hambaid ka lapse hälli juurde ja epideemiate ajal isegi kariloomadele kaela. Nagu kirjutab Leonid Potapov, olevat need tavad olnud usbekkidel au sees veel 1920.-1930. aastatel (Potapov 1958: 139-140). Täiskasvanud aga kandsid hundi hambaid kas kaelakeena või kõrvarõngastena. Seda tegid nii Siberi, Kesk-Aasia kui ka Euroopa rahvad. Mõned Siberi rahvad kandsid hundi- ja karukihvu veel vööl, et vältida valu teket nimmepiirkonnas (NES: 422). 
Hundi sabal oli oma osa täita nii armu- kui ka töömaagias. Antiikajast pärineva uskumuse järgi pidi hundi sabas olema eriline armastuse mahl (amatorium virus) - jõud, mis esinevat küll ainult elusal loomal (Die Naturgeschichte 1881: 107). Kas on tegemist kultuurilaenuga Lääne-Euroopast, pole selge, kuid ka Eestist on teada, et mehelemineku ikka jõudnud tüdrukuid on viheldud hundivõi rebasesabaga (ERA II 156, 30 (54) < Torma (1937)). Saunas seda toimingut läbi viies olevat neiu ema või mõni teine vanem naine lausunud:

Saagu, saagu saunakene, saagu sauna leilikene. Hirmu kakku, armukakku, läbi reide reinukakku, hundi sabaga vihelda, rebase sabaga võielda. Noorel neiul palju õnne, soovin palju peiusid (E $58790<$ Tarvastu (1921)).

Nagu on lisatud, ei kastetud seda saba vette, vaid viheldi kuivalt (Eisen 1934: $62-63)$.

Hundi sabast loodeti abi ka mujal peale armumaagia. Nii oli Muhu saare naistel kombeks käia võrgujahil tabatud hunti "lüpsmas" - ta saba läbi peo tõmbamas. Usuti, et kes hundi hända läbi peo tõmbab, selle käes sukad-kangad uhtuvad kangesti, s.t lähevad kergesti puhtaks. Kui hunt siin ükskord maha lastud, siis pandud aia peale Linnuse küla juures. Siis naised käin seal "hunti lüpsmas" (ERA II 191, 177 (4)< Muhu (1938)).

Teised rahvad kasutasid hundi saba, nagu koljutki, kaitsevahendina nii inimese enda kui ka tema loomade juures - ülesriputatuna kas tuvilasse, hobusetalli või mujale (Afanasjev 1965: 767; Klinger 1910: 246; Handwörterbuch 1987: 773).

Lõpuks ka karvade ja ekskrementide kasutamisest. Eestis tarvitati neid ainult väikelastel esineva nn hundivea ehk soetõve ravimiseks. See haigus pidi avalduma kas pea või käte värisemises, ülemäärases nutmises, kõõrdi vaatamises, keele laksutamises, lahtiste silmadega magamises, suures söögiisus ja lõrisemises rinna andmisel, sest latsel om suukene alati ammule ja ta habi niigu susi säält ja täält rõivaid, ehk ka rinda, nink ei saa sukugi süvva, ent on sisgi alati suureh näläh (H II 62, 349 (5) < Vastseliina (1899)). Arvati, et need hädad võis laps saada seetõttu, et hunt ehmatas või oli lapseootel ema kuulnud hundi hagemist või ulgumist.

Nu rasse jalalidse naise ku kävveve, siss iks pelgäsive nuid susse. Selle tu häd̈̈ oll vanast... (EKI, MT 76, 12/13 < Sangaste (1944)). 
Hundivea raviks oli hulk võtteid: last tuli kas suitsutada hundi karvade või ekskrementidega; pesta veega, kus oli lahustatud hundi ekskremente; anda lapsele juua hundi jäljest võetud lume sulamisvett või käia lapsega kolmel järjestikusel neljapäevaõhtul ristteel hunti hurjutamas (H II 43, 370 (23) < Suure-Jaani (1893)); H II 58, 274 (18) < Jüri (1897)); H II 64, 333 (79) < Torma (1901)); E 8378 (3) < Põlva (1893)); ERA II 1, 589 (11) < Reigi (1928)).

Üks ravivõte oli ka lapse hirmutamine:

Soetõpõ võivat ka nii ärr arsti, kui tuudi last, kel soetõbi um, soega jälle hiidütedes. Ma esi mäleta, kui ma väikene olli, viidi minnu üts kõrd välla, ku soe silma paisti, et ma sedä hiidüssi, sest mul olli kõõrdsilmä ja ma vahe viltu, midä soetõbes arvati (H II 51, 629 (5) < Vastseliina (1894)).

Peale hundivea tunti veel karu, jänese, orava, konna, ussi, linnu, siili, sea, lamba, koera, kassi, veise, hobuse ja teiste loomadega seotud vigu. Näiteks kui lapsel oli jänesemokk, kui ta magas lahtiste silmadega või oli väga arg, siis oli tal jäneseviga. Raviks tuli last suitsutada jänesekarvadega. Ajas laps käsi üle pea ja ringutas, oli tal oravaviga, keeras ta pead nagu uss, oli ussiviga jne (H II 30, 260 (7) < Rannu (1899)); E, StK 1, 184/5 (8) < Tõstamaa (1921)); ERA II 9, 291 (5) < Käina (1928)); E, StK 34, 84 (7) < Kursi (1926)).

Mujal maailmas kasutati hundi karvu ja ekskremente juba tõsiste haiguste puhul. Näiteks Kaukaasias kasutasid svaanid karvu langetõve puhul (Tšursin 1929: 9), ekskrementidest on Euroopas abi loodetud voolmete ehk koolikute korral nii inimestele kui ka hobustele, Bulgaarias Kjustendili piirkonnas olevat segatud ekskremente difteeria epideemia ajal isegi leivajahusse, millest küpsetatud leiba jagatud siis kogu külale (Gesner 1563: 155; Grosses vollständiges 1748: 509; Gura 1997: 154).

Kui kaua leidsid hundi kehaosad rahvaste hulgas veel kasutamist, kui kaua püsis usk nende imettegevasse võimesse? Kuigi otseseid andmeid selle kohta ei ole, saab aega kaudselt ikkagi määrata kasvõi Muhumaa hundijahtide kaudu, mille järel naised käisid tapetud hundi saba "lüpsmas". Neid jahte peeti seal veel 1850.-1860. aastatel. Juba nimetatud rahvaarsti Rööviku Kustas pidi olema meheks saanud 1880.-1890. aastatel, mil käidi tema juures abi saamas.

Mõnelgi teisel maal püsisid hundi kehaosad ravimina sel ajal veel au sees. Näiteks Gustav Heyeri väljaantud Allgemeine Forst- und Jagd-Zeitungi 1873. aasta aprillikuu numbri loos Pommeri hundist märgiti, et rahvameditsiin kasutab hundi organeid veel tänapäevalgi (Allgemeine 1973: 143-145). Sellest teatest 100 aastat varem kirjutasid hundi organite kasutamisest nii Jakob Bernhard Fischer (Fischer, 1772: 429 - kasutusel on palju ravimeid hundi verest, maksast, sooltest ja luudest) kui ka Carl Linné (Linné 1773: 222 - apteekides tarvitatakse palju hundi kehaosi: liha, rasva, südant, maksa, soolikaid). Sama kinnitasid ka prantsuse entsüklopedistid Denis Diderot ja Jean le Rond 
d'Alembert oma entsüklopeedia 20. köites hundist rääkides: talupojad ja kütid mü̈̈vad apteekritele hundi maksa (Encyclopedie ou Dictionnaire 1778: 415).

Rahvaste tavades olid hundi kõrval hinnatud loomulikult teistegi loomade organid ja organismi saadused. Nendest näiteks karu sapp, naaritsa rasv ja kopra nõre on tunnustatud ka nüüdisaja meditsiini poolt.

Hundist saadav abi ei piirdunud üksnes tema elunditega, seda võis loota ka hundilt endalt. Neil on nimelt komme hakata vahel inimesi saatma, omal ajal näiteks voorilisi - vahel kuni talu väravani välja. Kuidas see toimus kord Siberis, Tomski kubermangus, sellest I. Melnikovi mälestuste põhjal:

Kolmandat korda sõidan kuuvalgel ööl Aleksandrovist Tšubulovi külani ja iga kord kogu 25 versta pikkusel teel huntide konvoi saatel. [---]. Meie korteež paigutub juba kord väljakujunenud korra järgi [---]. Minust paremale ilmuvad tee lähedale 7, ette 3, taha tükki 5 ja vasakule 2 hunti. [---] Kuidas ka hobused ei liiguks, tasa või kiirelt, seavad hundid oma sammud hobuste järgi, rikkumata rivikorda. Peatumisel peatuvad meiega ühtlasi hundid. Meie ja huntide vahemaa on ka alati püsiv, mitte üle 50 sammu. Kõige huvitavam on seejuures, et meie hobused, kuigi iga kord vahetatavad, ei ilmuta mingeid ärevuse tundemärke. 4. jaanuaril, võttes ühes kaks kaheraudset laetud püssi, sõitsin ma välja juba kindla kavaga "kostitada” oma konvoid (Melnikov 1888: 10-11).

Nii ta ka tegi.

Niisuguses huntide tavas nägid eestlaste esivanemad ühte huntide positiivset külge - kaitsta inimesi üleloomulike olendite, kodukäijate, tontide, vanakurja ja teiste pahade vaimude eest. Sellepärast uskus rahvas, et kui hundid tikuvad sinu ligi jooksma, siis on su juures mõni kurivaim, kes sind kiusata püüab (E 33462 (308) < Otepää (1897)).

Võrumaal räägiti sellest nii:

Susi olevat alati inemise hoitja, kui ta teekä̈̈gi pääl üten kä̈̈p. Nii olli üts kõrd mees liinast kodo sõitnu ja kats sutt olliva mitukümme versta maad temaga kõrvusi käünu - üts ütel ja tõine tõisel pool. Kui mees jo pea ligi koto olevat saanu üte silla pääle, sääl karanu soe suure röä ja räbinaga, tõine tõisipooli silda kokko, õkva vanakurja pääle, keda na nahka pandnu. Jumalast olliva nee soe hoitjas saadetu, et vana kuri meest õige tee päält essitada es saa. Nii arvap ja usup vanarahvas parhillaki veel (H I 6, 772 (5) < Vastseliina (1895)).

Usuti sedagi, et hundid olevatki kodukäijate murdjaks loodud ja selleks olevat päris eri liik hunte - toonehundid ${ }^{2}$, kes lambaid ei puutuvatki (H I 4, 401 (3a) < Saaremaa (1874)); H III 27, 6 (3) < Lüganuse (1897)). 


\section{Hundi kujutamisest sümboolikal}

Hundi tähtsuse ilminguks on veel tema kujutamine lippudel, vappidel ja müntidel. Euroopa rahvaste vapiloomad ongi sageli olnud hunt ja karu. Hunt oli seal kui mehisuse sümbol - väsimatu ja vapper sõdur (Grosses vollständiges 1748: 515-516; Grimm 1876: 557).

Hunt oli ka mõne Eesti- ja Liivimaa aadlisuguvõsa vapiloomaks, tavaliselt neil, kelle perekonnanimi oli kas Hunt või esines sõna hunt liitnimes. Näiteks perekonnad Wolff, Wolffeld, Wulf, Wulffenschild, Wolframsdorf, kuid ka hoopis teise nimega aadlikel, nagu krahvid Strogonovid, rüütel Tuveson (Harju vasall aastal 1325), Like (Eestimaa kodanik aastal 1359), Zedeler (Tallinna kodanik aastal 1489) jt (Klingspor 1882).

Hundi kui türgi rahvaste tootemlooma pead kujutati nende khaanide lippudel. Nende ihukaitsjaidki kutsuti huntideks (Ivanov 1975: 407). Hunt on ka Tšetšeenia vapil sõjalise vapruse, mehisuse ja uljuse sümbolina (Entsüklopeedia 2001: 98).

Toodud ülevaade hundist meie rahva ülestähendatud pärimustes lubab teda näha loomana, kes on ka eesti folklooris oluliselt kohal. Mis on loomulik, arvestades, et tegemist on füüsiliselt tugeva, vastupidava ja vitaalse kiskjaga. Ka inimene omakorda pole jätnud hundile mõju avaldamata, muutes teda ökoloogiliselt üha plastilisemaks. Hundile annab sobiva hinnangu üle Eesti tuntud vanasõna: "Hundil on ühe mehe jõud, aga üheksa mehe aru."

\section{Kommentaarid}

${ }^{1}$ Euraasia tuntuimad hundirahvad, kelle silmis hunt oli tootemloom, on türklased ja mongolid.

2 Üldse eristasid inimesed meil mitut hundi tõugu: lamba- ja hobusehundid, vene- ja poolahundid, siis metsa-, paju-, susi- jt hundid. Aluseks nende kasv, karvkatte värvus ja pikkus ning käitumine. Rahvaluules eristatud toonehundid olevat olnud valged, ja nagu lisatud - lambaid ega ka inimesi ei puutunud (H I 4, 401 (3a) < Saaremaa - Eduard Kallas (1874); H III 27, 6 (3) < Lüganuse - J. Thomson (1897)).

\section{Käsikirjalised allikad}

\section{Eesti Kirjandusmuuseum (EKM)}

AES - Emakeele Seltsi murdetekstide kogu koopiad

E - M. J. Eiseni rahvaluulekogu (1880-1934)

E, StK - M. J. Eiseni stipendiaatide rahvaluulekogu (1921-1927)

ERA - Eesti Rahvaluule Arhiivi rahvaluulekogu (1927-1944) 
H - J. Hurda rahvaluulekogu (1860-1906)

RKM - Riikliku Kirjandusmuuseumi rahvaluulekogu (alates 1945. aastast)

SKS - Soome Kirjanduse Seltsi eesti rahvaluule kogu (1869-1912)

\section{Eesti Rahva Muuseum (ERM)}

KV - Korrespondentide vastuste arhiiv

\section{Eesti Keele Instituut (EKI)}

MT - Murdetekstide kogu

\section{Kirjandus}

Afanasjev 1865 = Афанасьев, Александр. Поэтические воззрения славян на природу. 1. Москва: К. Солдатенков.

Allgemeine 1873 = Allgemeine Forst- und Jagd-Zeitung. April. Frankfurt am Main: Gustav Heyer, lk 143-145.

Bernard, Daniel. 1983. Wolf und Mensch. Saarbrücken: Saarbrücker Dr. u. Verl.

Boecler, Johann Wolfgang 1854. Der Ehsten abergläubische Gebrauche, Weisen und Gewohnheiten. St. Petersburg: Buchdruckerei der kaiserlichen Akademie der Wissenschaften.

Böckler, Johann Wolfgang \& Einhorn, Paul \& Engelken, Friedrich 1857. Ueber die religiösen Vorstellungen der alten Völker in Liv- und Ehstland: drei Schriften von Paul Einhorn und eine von Johann Wolfgang Böckler, aufs neue wieder abgedruckt mit einer seltenen Nachricht Friedrich Engelken's über den grossen Hunger. Riga: Kymmel, lk 5556 .

Der Kleine Pauly 1975 = Wolf. Der Kleine Pauly: Lexikon der Antike. 5. München, lk 1387.

Die Naturgeschichte 1881 = Wittstein, $G$ [eorg] C[hristian] (tõlge ja kommentaarid). Die Naturgeschichte des Caius Plinius Secundus. 2: 8: 34, Leipzig: Gressner \& Schramm, lk 107.

Die Naturgeschichte 1882 = Wittstein, G[eorg] C[hristian] (tõlge ja kommentaarid). Die Naturgeschichte des Caius Plinius Secundus. 5: 28: 78, Leipzig: Gressner \& Schramm, lk 79 .

Dobrovolski 1901 = Добровольский, Владимир Н. Суеверия относительно волков. Этнографическое обозрение 51 (4).

Eisen, Matthias Johann 1934. Saun ja vihtlemine. Eesti Rahva Muuseumi aastaraamat VIII 1932. Tartu, lk 28-70.

$\mathrm{EM}=$ Экономической магазин. 15. Москва, 1783.

Encyclopedie ou Dictionnaire 1778 = Encyclopedie ou Dictionnaire raisonne des sciences, des arts et des metiers, Par une Societe des gens de Lettres. Diderot, Denis \& d'Alembert Jean le Rond (koost). Tome vingtieme. Geneve, lk 415. 
Entsüklopeedia 2001 = Волк. Энциклопедия символов, знаков, эмблем. Москва, lk 98 .

EV 1980 = Hussar, Anne (et alii koost). Eesti vanasõnad I 1-5000. Monumenta Estoniae antiquae. III, Eesti vanasõnad = Proverbia Estonica; 1. Tallinn: Eesti Raamat.

Fischer, Jakob Bernhard 1772. Liefländisches Landwirthschaftsbuch, auf die Erdgegend von Lief-, Est- und Curland, Riga und Leipzig. Riga: Hartknoch, lk 427-430.

Gesner, Conrad 1563. Thierbuch: Das ist ein kurtze Beschreibung aller vierfüssigen Thieren. Zürich: Froschover, lk 155.

Grimm, Jacob 1876. Deutsche Mythologie 2. Meyer, Elard H. (toim). Berlin: Dümmler, lk 557 [esmatrükk 1935 Göttingen: Dietrich].

Grosses vollständiges 1748 = Wolf. Grosses vollständiges Universal-Lexicon aller Wissenschafften und Künste. 58. Zedler, Johann Heinrich (koost). Leipzig und Halle, lk 508516.

Gubernatis, Angelo de 1874. Die Thiere in der indogermanischen Mythologie 1. Leipzig: Grunow, lk 452-453.

Gura 1997 = Гура, Александр. Символика животных в славянской народной традиции. Москва: Индрик.

Haruzin 1896 = Харузин, Алексей \& Харузин, Николай. Материалы для изучения древностей Эстляндской губерни. Москва, lk 13-14.

Haruzina 1909 = Харузина, Вера. Этнография. Курс лекций, чит. в Моск. археол. ин-те и на Высш. жен. курсах в Москве. І. Москва.

HDA = Hoffmann-Krayer, Eduard \& Bächtold-Stäubli, Hanns (koost) 1987 [19271942]. Wolf. Handwörterbuch des deutschen Aberglaubens. 9. Berlin, lk 768-782.

Ivanov 1975 = Иванов, Вячеслав. Реконструкция индоевропейских слов и текстов, отражающих культ волка. Известия Академии Наук СССР. Серия литературы и языка. 34: 5, lk 399-408. (vt ka http://feb-web.ru/feb/izvest/1975/05/755-399.htm - 29. november 2008.)

Jaanits, Lembit 1961. Jooni kiviaja uskumustest. Jansen, Ea (koost). Religiooni ja ateismi ajaloost Eestis. Artiklite kogumik II. Tallinn: Eesti Riiklik Kirjastus, lk 5-70.

Jermolov 1905 = Ермолов, Алексей. Народная сельскохозяйственная мудрость в пословицахь, поговоркахь и приметахь. III. Животный мир в воззрениях народа. С.-Петербург.

Klinger $1910=$ Клингер Витольд. Животное в античном и современном суеверии. Университетскія Известия. 11 (ноябрь). Киев: тип. Имп. Ун-та св. Владимира АО печ. и изд. дела Н.Т. Корчак-Новицкого.

Klingspor, Carl Arvid 1882. Baltisches Wappenbuch. Wappen sämmtlicher, den Ritterschaften von Livland, Estland, Kurland und Oesel zugehöriger Adelsgeschlechter. Stockholm: F. \& G. Beijer.

Linné, Carl. 1773. Vollständiges Natursystem. 1. Von den säugenden Thieren. Nürnberg, lk 222 . 
Luce, Johann Wilhelm Ludwig 1827. Wahrheit und Muthmassung. Beitrag zur ältesten Geschichte der Insel Oesel. Pernau: Marquardt.

Marahwa Näddala-Leht 1823, 9. veebruar.

Melnikov 1888 = Мельников, И. И. Волчьи сцены (моменты из встречь с волками). Природа и Охота 1888 (декабрь).

Moora, Harri (koost) 1926. Eestlaste kultuur muistsel iseseisvus-ajal. Tartu: Loodus.

Morozova 1973 = Морозова, М. Н. Скандинавские и финские лопари. Календарные обычай и обряды в странах зарубежной Европы. XIX - начало XX в. Зимние праздники. Москва, lk 136-139.

$\mathrm{NES}=$ Волк. Новый энциклопедический словарь. 11. С.-Петербургь, б. Г, lk 421422 .

Onomatologia $1773=$ Wolf. Otto, Christoph \& Stahl, Johann Friedrich (koost). Onomatologia forestalis-piscatorio-venatoria oder vollständiges Forst-Fisch und Jagd-Lexicon. 3. Frankfurt \& Leipzig, lk 1015-1016.

Potapov 1958 = Потапов, Леонид П. Волк в старинных народных поверьях и приметах узбековю Институт этнографии имени Н. Н. Миклухо-Маклая. Краткие сообщения, $X X I X$. Москва.

Rantasalo, Aukusti Vilho 1919. Der Ackerbau im Volksaberglauben der Finnen und Esten, mit entsprechenden Gebräuchen der Germanen verglichen 2. Folklore Fellows Communications 31. Sortavala: Suomalainen Tiede-akatemia.

Russwurm, Carl Friedrich Wilhelm 1855. Eibofolke, oder, Die Schweden an den Küsten Ehstlands und auf Runö: eine historisch-ethnographische von der Kaiserlichen Akademie der Wisserschaften zu St. Petersburg mit einem demidowschen Preise gekrönte Untersuchung. 1. Reval: J. J. Kelchen.

Sabanejev 1872 = Сабанеев, Леонид П. Звериный промысель в Уральских горах. Беседа. ЖКрналь ученый, литературный и политический. 6. Москва.

Saksen, Aleksander 1842. Lomisse Öppetusse-ramat, kus sees ärraselletakse, mis suur Jummal mailma peäle on lonud. Iggaühhele, kes öppetust tagganouab. Tallinn: J. H. Gressel.

Zelenin 1929 = Зеленин, Д. К. Табу слов у народов восточной Европы и северной Азии. I. Запреты на охоте и иных промыслах. Сборник музея антропологии и этнографии. VIII. Ленинград.

Tolstoi 1995 = Толстой, Никита И. (toim). Славянские древности. Этнолингвистический словарь. 1. (А-Г) Москва: Международные отношения lk 416.

Tšursin 1929 = Чурсин, Г. Ф. Амулеты и талисманы кавказских народов. Махачкала.

Volk 1985 = Бибиков, Дмитрий (vastutav toimetaja). Волк: Происхождение, систематика, морфология, экология. Москва: Наука. 


\section{Summary}

\section{Wolf as an Animal of Worship in Estonian Folk Tradition}

\section{Ilmar Rootsi}

Key words: breeding, euphemisms, help and protection, natural forces, respect, right to living, right to catch, sacrifice

Actual worship or veneration of wolf is not known in Estonian folk tradition. Wolf is a wild animal and oral lore about it, which has sprung from herding lore, is versatile and affluent. In the Estonian tradition, wolf was a force of nature that had to be considered - and respected. Already the large number of euphemisms about the wolf is evidence of the great respect for this animal.

The veneration of wolf as a predator is described in several Estonian lore texts as follows:

(a) people recognised its right to catch. For this purpose each farm allotted a portion of its produce for the wolf;

(b) because the wolf's right to catch, disturbing, or even scolding a wolf departing with a catch was prohibited;

(c) a wolf's catch could not be used;

(d) people believed that by slaughtering domestic animals, a wolf also encourages their breeding;

(e) when a wolf was encountered, it had to be addressed in kind words;

(f) people were afraid of ravaging a wolf's den for fear of revenge.

A wolf - parts and substances of his body and the animal itself - was expected to provide help and protection. The narratives mention wolf's flesh, throat, skull, fangs, tail, hair and faeces. These were believed to help people to cure their ailments, ensure success and luck in household chores, work, offer protection against evil forces and bring luck in personal life.

In Estonian folk medicine, wolf meat has been used to cure rheumatism; a person who ate its meat was believed to get the magical power to heal other people. Throat was used for beekeeping and growing crops. The skull was kept in the granary as a protective charm. Fangs were used for two purposes: to speed up babies' teething and as amulets or charms. Tail was used in both love and work magic. Wolf's hair was used for treating typhoid fever (hundiviga, soetõbi, literally 'wolf's disease'). Excrements were used for treating colic.

People expected wolf itself to offer help. When they were seen accompanying a traveller, people believed that this is their way of protecting people against all kinds of malevolent spirits (revenants, ghosts, devils and others) who try to spite people. It was believed that the wolves that protected people were of special kind: toonehundid, or wolves of the underworld, which did not kill sheep.

Wolf is also featured on the coats-of-arms of some Estonian and Livonian families. 